\title{
INEQUALITIES FOR NORMS OF SOME INTEGRAL OPERATORS
}

\author{
A. G. RAMM
}

Abstract. Let $(A(a) u)(x):=\int_{0}^{a}(1-x t)^{-1} u(t) d t, 0<a<1$. Properties of the operators $A(a)$ as $a \rightarrow 1$ are studied. It is proved that $A:=A(1)$ is a bounded, positive self-adjoint operator in $H=L^{2}[0,1],\|A\| \leqslant \pi$, while $A: C(0,1) \rightarrow C(0,1)$ is unbounded. equation.

Mathematics subject classification (1991): 35R30.

Key words and phrases: Integral operators, inequalities, estimates of the norm, Symm's integral

\section{REFERENCES}

[1] Hardy, G., LitTlewood, J., Polya, G., Inequalities, University Press, Cambridge, 1952.

[2] Kantorovich, L., AKILOV, G., Functional analysis in normed spaces, Pergamon, New York, 1964.

[3] KRASNOSElSKII, M., ET AL., Integral operators in the spaces of summable functions, (p. 90), Noordhoff, Leyden, 1976.

[4] Shivakumar, P., Diagonally dominant infinite matrices in linear equations, Util. Math 1 (1972), 235-248.

[5] WIDDER, D., An introduction to transform theory, Academic Press, New York, 1971.

[6] Halmos P. AND Sunder V., Bounded integral operators on $L^{2}$-spaces, Springer-Verlag, New York, 1978. 